Dossiê Especial: Experiências do PIBID na formação inicial e continuada de professores de línguas estrangeiras

HIBARINO \& NODARI (orgs)

Revista X, vol.1, 2015

\title{
AUTOAVALIAÇÃO E AVALIAÇÃO DOCENTE NO PROCESSO DE APRENDIZAGEM: UMA EXPERIÊNCIA NO PIBID - INGLÊS DA UFPR
}

Self-assessment and teacher evaluation in the learning process: an experience in the PIBID English at UFPR

Katia Bruginski MULIK ${ }^{1}$

Juliana Pedrollo VIANI ${ }^{2}$

Resumo: Este texto apresenta uma experiência do PIBID - Inglês da UFPR realizada em uma das escolas parceiras do projeto. Inicialmente, apresentamos as razões que levaram à utilização de um instrumento de autoavaliação e outro de avaliação docente nas aulas de língua inglesa, aplicados no final do ano letivo de 2013, em uma turma de sexto ano do Ensino Fundamental. Em seguida, mostramos como as respostas dos alunos influenciaram nossas práticas no ano letivo de 2014. Por meio do desenvolvimento do Letramento Crítico e da utilização da autoavaliação e avaliação docente percebemos mudanças positivas por parte dos alunos em relação à motivação e à aprendizagem em um sentido amplo.

Palavras-chave: avaliação; autoavaliação; ensino de língua inglesa; PIBID.

Abstract: This text presents an experience in the PIBID - English at UFPR carried out in one of the partner-schools of such project. Initially, we present the reasons that led to the use of an instrument of self-assessment and one of teacher evaluation in the English classes, applied at the end of 2013 in one group of sixth graders of elementary school. After that, we present how the answers provided by the students influenced our practices in the school year of 2014. By means of the development of Critical Literacy and the use of self-assessment and teacher evaluation we noticed positive changes in the students' behavior especially in regards to their motivation and in their learning in a wider sense.

Keywords: evaluation; self-assessment; teaching of English; PIBID.

\section{Introdução}

No ano de 2013 o PIBID - Inglês da UFPR realizou trabalhos tanto no Ensino Fundamental e Médio quanto no Ensino de Jovens e Adultos (EJA) na escola Algacyr Munhoz Maeder, localizada no Bairro Alto da cidade de Curitiba, estado do Paraná. Um desses projetos

\footnotetext{
${ }^{1}$ Mestre em Letras pela Universidade Federal do Paraná. Professora de língua inglesa na rede pública do Estado do Paraná.katiamulik@yahoo.com.br

${ }^{2}$ Graduanda em Letras pela Universidade Federal do Paraná. jupviani@gmail.com
} 
Dossiê Especial: Experiências do PIBID na formação inicial e continuada de professores de línguas estrangeiras

HIBARINO \& NODARI (orgs)

Revista X, vol.1, 2015

foi realizado com uma turma de $6^{\circ}$ ano no Ensino Fundamental. $\mathrm{O}$ grupo acompanhou o trabalho da professora e se envolveu gradualmente na rotina da sala de aula, fazendo, no começo, muitas observações e, aos poucos, realizando pequenas atividades nas aulas daquela que seria também a professora supervisora no projeto PIBID - Inglês.

Para que esse trabalho pudesse ter continuidade, foi decidido entre os membros do grupo que no ano seguinte trabalharíamos com a mesma turma e com uma proposta mais bem definida, na qual a supervisora nos permitiria maior autonomia e auxiliaria desde a preparação das aulas até a elaboração e correção das propostas de avaliação. Para realizar um trabalho que pudesse atender as reais necessidades dos alunos, decidimos fazer um levantamento sobre alguns aspectos específicos das aulas de língua inglesa (LI) para direcionarmos nosso planejamento.

Assim, no último dia de aula de língua inglesa no ano de 2013, distribuímos um questionário com dez perguntas que visavam identificar a compreensão dos alunos em relação às explicações e às atividades, se apreciavam as propostas e como avaliavam seus conhecimentos em LI. Além disso, solicitamos que avaliassem o desempenho dos professores (no caso a professora supervisora/regente e os bolsistas do PIBID), apontando pontos positivos e negativos, bem como sugestões que pudessem ser incorporadas em nossas práticas futuras.

O objetivo deste texto é fazer um relato sobre o processo de aplicação da avaliação docente e autoavaliação nas aulas de LI e levantar quais foram os seus impactos tanto na aprendizagem dos alunos quanto na elaboração das propostas pedagógicas. Nosso artigo está dividido em seis partes. Após esta breve introdução, discutiremos alguns aspectos teóricos referentes ao processo de avaliação e autoavaliação na aprendizagem. Em seguida, caracterizaremos o contexto, bem como o perfil dos alunos envolvidos. Depois apresentaremos as respostas dadas pelos alunos aos nossos questionamentos e, por último, os impactos dessas atividades na aprendizagem dos estudantes e em nossa prática pedagógica, seguidos das considerações finais.

\section{Avaliação e autoavaliação no processo de aprendizagem}

No contexto escolar o ato de avaliar se faz constante. No entanto, nem sempre é encarado de forma positiva pelos professores, uma vez que involve questões como elaboração de 
Dossiê Especial: Experiências do PIBID na formação inicial e continuada de professores de línguas estrangeiras

HIBARINO \& NODARI (orgs)

Revista X, vol.1, 2015

instrumentos avaliativos, correções de atividades, lançamento de notas ou conceitos, entre outros procedimentos. Além disso, em alguns casos, a avaliação é interpretada como uma forma de punição diretamente relacionada ao fator indisciplina. A pesquisadora Jussara Hoffman explica que

(...) para inúmeros professores, pela sua história de vida e por várias influências sofridas, a avaliação se resume à decisão de enunciar dados que comprovem a promoção ou retenção dos alunos. É uma penosa obrigação a cumprir na sua profissão, que deve ser exercida da forma mais séria (rígida?) possível e no menor tempo que possam dispor! (HOFFMAN, 2009, p. 22)

Porém, se partimos de uma concepção de avaliação que leva em conta apenas momentos estanques e artificiais de aplicação de provas e atividades, o sentido diagnóstico esvazia-se. Assim como ensinar e aprender se caracterizam como algo processual, avaliar é um dos aspectos inseridos nesse processo. Segundo Hoffman (2009), a avaliação deve ser concebida como uma ação mediadora e para isso a autora sugere alguns princípios norteadores da prática, tais como: oportunizar momentos de discussão diversificados para os alunos expressarem suas ideias; realizar uma gama significativa de tarefas e analisar as respostas dos alunos, não apenas na questão do conteúdo, mas os "porquês" das respostas dadas; evidenciar comentários nas tarefas e não apenas atribuir certo ou errado ao que o aluno respondeu, para que ele compreenda o motivo dos seus acertos e erros e, por fim, utilizar os registros de avaliação como forma de acompanhar os estudantes diante do seu processo de aprendizagem e construção do conhecimento.

Fred Genesee e John Upshur (2009) defendem que o ato de avaliar implica primeiramente em tomar decisões que por ventura venham a se constituir nas escolhas feitas para melhorar o desempenho dos estudantes. Para esses autores, depois de definir o propósito da avaliação, há outros três componentes básicos: informação, interpretação e tomada de decisões (ver figura 1), já que "informações sobre aprendizagem e ensino raramente têm sentido em si mesmas. Elas adquirem sentido quando são interpretadas. Interpretações significativas são necessárias para decidir que ações e mudanças serão feitas 3". (GENESEE \& UPSHUR, 2009, p. 4).

São os instrumentos de avaliação que nos fornecem informações sobre a aprendizagem de

3 No original: "Information about teaching and learning is rarely meaningful by itself. It becomes meaningful when it is interpreted. Meaningful interpretations are needed in order to decide what actions to take or what changes to make." 
Dossiê Especial: Experiências do PIBID na formação inicial e continuada de professores de línguas estrangeiras

HIBARINO \& NODARI (orgs)

Revista X, vol.1, 2015

nossos alunos. Segundo as pesquisadoras Ivete Morosov e Juliana Martinez, "o aluno precisa ter contato com diferentes formas de avaliação para que possa desenvolver o processo de aprendizagem e consequentemente a avaliação seja satisfatória para o seu desempenho" (MOROSOV \& MARTINEZ, 2008 p. 91). Assim, uma prova escrita pode constituir uma forma de saber se o aluno conseguiu compreender e/ou se foi capaz de aplicar determinado conteúdo ao que foi solicitado pelo professor. Porém as respostas que os alunos nos fornecem dizem respeito não apenas à aprendizagem deles, mas também à forma como ensinamos, pois avaliar e ensinar são elementos que caminham juntos.

Portanto, nem sempre o fato de os alunos terem se saído mal em uma avaliação está ligado ao desinteresse ou falta de assimilação do conteúdo. Às vezes, o desempenho baixo pode estar relacionado à metodologia utilizada pelo professor ou até mesmo à má formulação da proposta de avaliação. A etapa de interpretação dos resultados das avaliações é crucial para que as tomadas de decisões possam ocorrer, e devem ser feitas em parceria com os alunos.

De acordo com os pesquisadores Genesee \& Upsher (2009), os aspectos envolvidos na avaliação podem ser estruturados da seguinte forma:

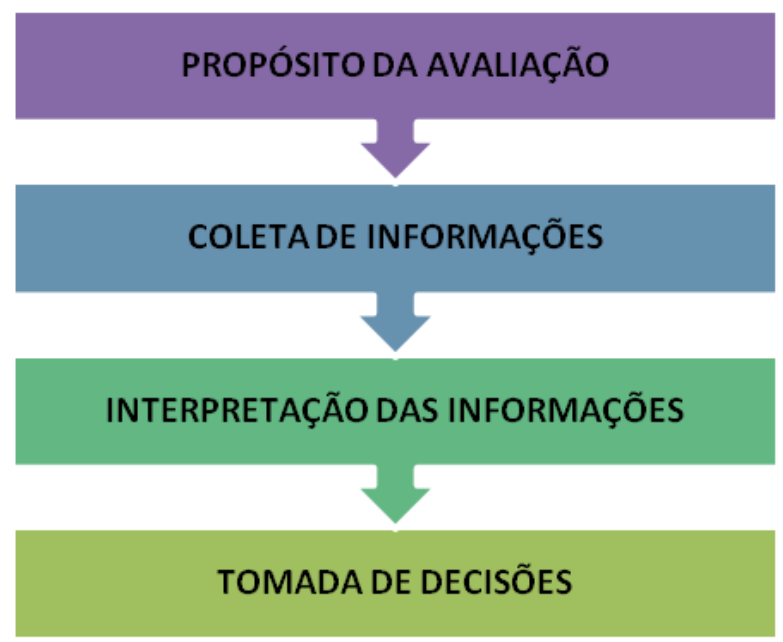

Figura 1 - Aspectos da avaliação em sala de aula - GENESEE \& UPSHUR (2009)

Partindo de uma concepção contemporânea (SILVA, BARTHOLOMEU \& CLAUS, 2007) a avaliação deve ir além do uso de instrumentos para avaliar alunos, professores e instituições e contemplar outras formas alternativas que preveem uma continuidade. Dentre essas 
Dossiê Especial: Experiências do PIBID na formação inicial e continuada de professores de línguas estrangeiras

HIBARINO \& NODARI (orgs)

Revista X, vol.1, 2015

formas encontra-se o uso da autoavaliação. Para que este instrumento seja bem sucedido, é

preciso que os envolvidos saibam quais são os objetivos das questões, bem como da autoavaliação como um todo, pois se for utilizada de "maneira impressionista, em vez de ser um instrumento de desenvolvimento, poderá se tornar fonte de desentendimento." (SILVA, BARTHOLOMEU \& CLAUS, 2007, p. 90).

A utilização da autoavaliação pode trazer opiniões controversas já que, por um lado os professores podem acreditar que os alunos não possuem maturidade suficiente para emitir opiniões sobre sua aprendizagem ou ainda sobre a maneira como percebem seus professores. Por outro lado, ao estarem envolvidos numa atividade que exige reflexão, os alunos podem se sentir mais responsáveis pelo próprio processo de aprendizagem, desenvolvendo sua capacidade autocrítica. Para Mitre et. al (2008, p. 2137) “o estudante precisa assumir um papel cada vez mais ativo, descondicionando-se da posição de mero receptor de conteúdos, buscando efetivamente conhecimentos relevantes aos problemas e aos objetivos da aprendizagem." Os autores ainda continuam:

Na auto avaliação, pode-se rever a metodologia utilizada na prática pedagógica, enquanto o discente irá refletir sobre si mesmo e a construção do conhecimento realizado. O momento do diálogo servirá para reflexão sobre a relação e a interação entre docente e discente, no ato comum de conhecer e reconhecer o objeto de estudo, agora não mais numa relação verticalizada e estática, mas numa construção dialógica. (MITRE et. al, 2008, p. 2138).

Mitre et. al enfatizam a importância do diálogo entre docente e discente como forma de reduzir o aspecto assimétrico presente do processo de ensino e aprendizagem, uma vez que dessa forma não é apenas o professor que pode e sabe sugerir melhores formas de aprendizagem, mas o aluno, a partir do seu engajamento no processo se torna capaz de perceber quais estratégias podem ou não "funcionar", e assim, sugerir que o professor evidencie esses aspectos/estratégias em suas aulas.

Douglas Brown (2004) coloca que a autoavaliação apresenta uma série de princípios norteadores. Um deles seria a questão da autonomia entendida como aspecto primordial para uma aprendizagem bem sucedida. Para o autor, o desenvolvimento da motivação intrínseca também é outro aspecto que deve estar no topo da lista para uma aprendizagem bem sucedida. Brown apresenta diferentes tipos de autoavaliação e seus respectivos objetivos: 
Dossiê Especial: Experiências do PIBID na formação inicial e continuada de professores de línguas estrangeiras

HIBARINO \& NODARI (orgs)

Revista X, vol.1, 2015

- autoavaliação de participação em sala (self-assesssment of class participation): traz questões relacionadas à assiduidade, realização de exercícios em sala, frequência de questionamentos feitos ao professor, envolvimento nos debates e discussões, atenção durante as explicações, entre outros. Nesse tipo de autoavaliação os alunos respondem às questões que são feitas de forma objetiva com opções em forma de escala, por exemplo, sempre - às vezes - nunca. As respostas fornecidas contribuem para que o professor, bem como o aluno, avaliem melhor sobre seu engajamento em sala.

- autoavaliação dos objetivos da aula (self-assessment of lesson objectives): feita em forma de lista engloba os principais objetivos da aula ou de um conjunto de lições, as quais os alunos precisam sinalizar dentro de uma escala ( $\operatorname{sim}$ - às vezes - ainda não) se esses aspectos ou conteúdos já foram ou não assimilados. Se uma das questões for, por exemplo, "Eu sei utilizar diferentes expressões sobre o tempo" (I can say the time in different ways) e o aluno sinalizar que 'não', o professor tem a oportunidade de trabalhar de forma mais individualizada ou de saber que precisa retomar esse conteúdo, no caso de uma grande maioria sinalizar a mesma alternativa.

- autoavaliação sobre estilos de aprendizagem (self-assessment of styles): apresenta questões sobre as preferências dos alunos, que podem estar relacionadas à metodologia utilizada pelo professor ou sobre comportamentos em sala, por exemplo, "Eu tenho vergonha quando alguém ri de mim no momento em que eu falo" (I get embarrassed if people laught at me when I speak).

- autoavaliação sobre as múltiplas inteligências (self-assessment of multiple intelligences): engloba diferentes questões relacionadas às múltiplas inteligências com perguntas do tipo: "Eu gosto de cantar e ouvir músicas em inglês" (inteligência musical), "Eu gosto de realizar atividades em pares ou grupos" (inteligência interpessoal). Ao considerar as múltiplas inteligências e buscar evidenciá-las na aprendizagem dos alunos o professor reconhece a individualidade dos estudantes, pois "da mesma maneira que o professor tem seu próprio perfil de inteligências, podendo afetar a forma como ensina, os alunos têm um perfil próprio de aprendizagem que pode afetar a forma como aprendem." (CABRAL \& MULIK, 2014, p. 63). 
Dossiê Especial: Experiências do PIBID na formação inicial e continuada de professores de línguas estrangeiras

HIBARINO \& NODARI (orgs)

Revista X, vol.1, 2015

- autoavaliação sobre as preferências na aprendizagem (self-assessment of leaning preferences): esse tipo de autoavaliação fornece informações tanto para o professor quanto para o aluno a fim de poder identificar quais são os estilos prediletos, especialmente após ter diagnosticado as preferências dos alunos buscando compensar os estilos que foram menos recorrentes. Nesse sentido, os alunos, diante de um conjunto de afirmações do tipo "Trabalho em grupo", "Trabalho individual", "Leitura", entre outros, sinalizam os fatores que contribuíram na aprendizagem daquela lição ou conjunto de lições.

Há, portanto, vários tipos de autoavaliação que apresentam objetivos distintos e podem ser utilizadas, de forma individual ou em conjunto, para fornecer informações cruciais para que o professor possa planejar suas aulas atendendo às necessidades dos alunos. A autoavaliação pode ser uma aliada também para que o professor possa compreender, de forma mais individualizada, o próprio processo de aprendizagem dos estudantes, sem esquecer que os alunos, ao se autoavaliarem, também se tornam mais conscientes desse processo e consequentemente mais autônomos. A atividade aplicada no sexto ano citado neste artigo se propôs a ser uma mistura dos diferentes estilos de autoavaliação citados por Brown, e visou coletar o maior número possível de informações no sentido de embasar nossas escolhas para um planejamento cuidadoso do que deveria ser feito, uma vez que solicitava a avaliação de atividades que havíamos acompanhado enquanto bolsistas realizando observações de aula.

\section{$O$ contexto e o perfil dos alunos participantes}

Os alunos com os quais trabalhamos estudam no Colégio Estadual Professor Algacyr Munhoz Maeder. Fundado em 1978, seu nome faz homenagem a um importante defensor da educação, que chegou a ser reitor da Universidade Federal do Paraná. O colégio trabalha com Ensino Fundamental II, Ensino Médio e Educação de Jovens e Adultos (EJA), atendendo a comunidade nos três turnos.

Os alunos ingressantes do sexto ano e que responderam ao nosso questionário não haviam tido ainda contato formal com a LI, pelo menos não na escola. Isso exigia maior dedicação no trabalho dos professores, que se tornavam responsáveis por inserir o aluno na aprendizagem dessa 
Dossiê Especial: Experiências do PIBID na formação inicial e continuada de professores de línguas estrangeiras

HIBARINO \& NODARI (orgs)

Revista X, vol.1, 2015

nova disciplina, preparando-os para as próximas séries.

A clientela atendida pela instituição é bem diversificada e o perfil dos alunos também varia de acordo com o turno em que o estudante se insere. A maioria dos alunos são oriundos de famílias de classe média baixa e os responsáveis raramente possuem ensino superior (conforme informações advindas do PPP da escola). A composição familiar mais comum é de estudantes que moram com a mãe provedora, mas também uma parte mora com a mãe e os avós, com os pais ou, em raríssimos casos, apenas com o pai ou com um tutor. Assim, nossas atividades precisariam sempre estar adequadas às condições de nossos alunos, mas também precisávamos manter em mente que a aula deveria ser um polo de extrema exposição à LI, a fim de compensar o possível contato diminuto que eles mantinham com o idioma fora do ambiente escolar.

A turma $6^{\circ} \mathrm{B}$, considerada tranquila mesmo com eventuais momentos de agitação absolutamente típicos da faixa etária que não atrapalhavam o andamento das atividades, era composta por 25 alunos entre 10 e 11 anos. Durante as aulas, tínhamos em sala a professora supervisora, quatro bolsistas atuantes no projeto e um bolsista voluntário com atuações esporádicas. A turma apresentava poucos alunos retidos, ou seja, que estavam refazendo a série. Inquestionavelmente, os alunos eram muito dedicados e comprometidos, produziam bastante, precisavam de poucas orientações para realizar as atividades, demonstrando autonomia e bastante interesse, sendo que em certo momento do ano, tivemos que recorrer à utilização de exercícios em livros didáticos do Ensino Médio, pois os destinados ao $6^{\circ}$ ano e Ensino Fundamental, em geral, estavam muito fáceis para a turma que dispersava muito rápido após a realização destes.

A característica mais importante do PIBID - Inglês, e que veio a ser uma característica importante também para a turma, é a aplicação de pressupostos do LC em suas propostas, o que foi responsável por criar um ambiente propício para o desenvolvimento da atividade com sucesso. O LC não foca apenas nos aspectos comunicativos imediatos da língua, mas visa uma atribuição e construção de sentidos que conferem significado ao texto para o indivíduo, fazendo-o pensar a respeito dos contextos de escrita e leitura do texto, sendo fundamental o debate a respeito de características sociais, políticas, culturais e ideológicas das circunstâncias da leitura (JORDÃO, 2013).

As diferenças ideológicas, para o LC, são tidas como aspectos produtivos do poder, pois cada uma delas é considerada melhor ou pior do que as outras conforme se adequem a sistemas de 
Dossiê Especial: Experiências do PIBID na formação inicial e continuada de professores de línguas estrangeiras

HIBARINO \& NODARI (orgs)

Revista X, vol.1, 2015

valores diferentes (JORDÃO, 2013). O choque de ideias ou entre visões de mundo também é apontado como algo construtivo por Markus Weininger (2006), que compara o mundo ao mar aberto e a sala de aula a um aquário. Sendo as águas do mar aberto muito mais agitadas que as paradas águas do aquário, é importante que exista esse tipo de conflito para que o ambiente da sala de aula tenha suas águas agitadas e, assim, simular o mar aberto, preparando o aluno para os conflitos do mundo. Promover o contato com outras perspectivas é oportunizar uma aprendizagem transformadora do modo de interpretar o mundo, e procurar soluções para os eventuais problemas encontrados.

O LC tem como base, também, a localização de problemas e a suas efetivas soluções. A pesquisadora Clarissa Jordão (2013) afirma que, para isso, é necessário identificá-los, formulando questionamentos críticos e buscando:

(...) entender os pressupostos e implicações de nossas realidades. As soluções que geramos a partir desses processos precisam ser analisadas reconhecendo-se que elas serão sempre respostas locais a problemas locais, que não perdem sua importância ao serem concebidos em sua parcialidade e seu caráter contextual. (JORDÃO, 2013, p. 44).

Sendo assim, o uso da autoavaliação se encaixa como uma das alternativas constantes no perfil de desenvolvimento do LC, pois é uma atividade na qual ocorre um processo de identificação de problemas e meios de solucioná-los. Entende-se que a reflexão provocada pelos questionamentos leva os alunos a pensarem com cuidado sobre seu papel como agentes no processo de ensino e aprendizagem de uma língua estrangeira.

\section{Instrumento de diagnóstico e discussão dos resultados}

\subsection{Autoavaliação}

A atividade de autoavaliação foi aplicada no último dia de aula. No entanto, como alguns alunos já haviam sido aprovados em todas as disciplinas e estavam liberados para as férias participaram do exercício apenas 22 dos 25 alunos. Preparamos uma folha com dez itens que poderiam ser respondidos de acordo com quatro parâmetros: Sempre (S), Geralmente (G), Às 
Dossiê Especial: Experiências do PIBID na formação inicial e continuada de professores de línguas estrangeiras

HIBARINO \& NODARI (orgs)

Revista X, vol.1, 2015

vezes (A), Ainda não (AN). Os resultados encontram-se no quadro 1.

\begin{tabular}{lcccc}
\hline \multicolumn{1}{c}{ QUESTÕES } & SEMPRE & GERAL- & ÀS & AINDA \\
& & MENTE & VEZES & NÃo \\
1) Eu gosto das minhas aulas de inglês. & 11 & 3 & 8 & 0 \\
2) Eu consigo entender palavras simples em inglês. & 8 & 2 & 12 & 0 \\
3) Eu gosto de ouvir e de participar das histórias. & 7 & 8 & 6 & 1 \\
4) Eu consigo falar algumas palavras em inglês. & 4 & 10 & 8 & 0 \\
5) Eu trabalho bem com meus colegas. & 13 & 3 & 5 & 1 \\
6) Eu consigo entender as explicações das minhas & 9 & 2 & 11 & 0 \\
professoras. & & & & \\
7) Eu consigo entender os conteúdos. & 6 & 6 & 10 & 0 \\
8) Eu participo das canções e jogos. & 8 & 3 & 7 & 4 \\
9) Eu consigo fazer os exercícios das minhas folhas & 13 & 6 & 3 & 0 \\
de atividades. & & 6 & 8 & 2 \\
10) Eu me considero muito bom nas aulas de inglês. & 6 & 6 & \\
\hline
\end{tabular}

Quadro 1 - Resultados da atividade de autoavaliação

Uma leitura prévia em conjunto com a turma e breve explicação dos itens foi necessária para evidenciar os aspectos analisados, mas sempre deixando espaço para interpretações individuais. Por exemplo, a questão “2) Eu consigo entender palavras simples em inglês” visa um uso instrumental da língua, ou seja, sua forma escrita, porém deixamos em aberto para os que as já conseguiam identificar em forma falada analisarem segundo esse aspecto. Os itens "6) Eu consigo entender as explicações das minhas professoras." e "7) Eu consigo entender a matéria" são completares uma vez que tínhamos 5 professores em sala e queríamos saber o impacto que isso gerava na compreensão dos conceitos. E, por fỉm, o item 10 estava relacionado à individualidade da turma, já que sempre que alguém participava da aula ou obtinha bons resultados nas avaliações, os colegas o incentivavam ressaltando que aquele aluno era "bom de inglês", logo esse item tem a ver com rendimento escolar.

Percebemos que, mesmo com muitas respostas positivas, aspectos que precisavam ser aprimorados também apareceram. Nos tópicos "2 - Eu consigo entender palavras simples em inglês" e "10 - Eu sou muito bom nas aulas de inglês" encontramos um resultado duvidoso. Percebemos que os alunos têm dificuldade em identificar e mesmo aceitar que sabem os 
Dossiê Especial: Experiências do PIBID na formação inicial e continuada de professores de línguas estrangeiras

HIBARINO \& NODARI (orgs)

Revista X, vol.1, 2015

conteúdos, enquanto na realidade, o output apresentado, ou seja, as respostas aos estímulos, eram quase sempre além das expectativas. Em "8 - Eu participo das canções e jogos” já esperávamos um resultado não tão bom, porque nas nossas aulas raramente trazíamos jogos, músicas ou histórias para as crianças; quase sempre trazíamos textos com pouco potencial lúdico. Esse item foi necessário não pelas respostas em si, mas pela discussão gerada em torno desse tema.

Já a resposta para o item "1 - Eu gosto das minhas aulas de inglês." nos causou surpresa. Apesar do índice de respostas "Às vezes (A)" e "Ainda não (AN)" não ser alto, optamos por rever o conceito das atividades propostas, buscando agora alternativas com maior potencial lúdico e interativo, a fim de desenvolver, cada vez mais, o interesse dos alunos. Para os itens "6 - Eu consigo entender minhas professoras" e "7 - Eu consigo entender a matéria" o resultado nos fez pensar o motivo pelo qual os alunos não costumam manifestar suas dúvidas, mesmo com nossos constantes pedidos. Provavelmente essas respostas têm a ver com o receio que os alunos apresentavam temendo comentários jocosos dos colegas e também por eles terem quatro e às vezes cinco participantes (supervisora e bolsistas do PIBID) do projeto em sala. Sempre tivemos a impressão de que os alunos poderiam se sentir um pouco "perdidos" sobre em relação a quem perguntar ou a quem atender.

Quanto aos itens “3- Eu gosto de ouvir e de participar das histórias.”, “4- Eu consigo falar algumas palavras em inglês." o resultado obtido ficou dentro do esperado, já que o foco das aulas não era o desenvolvimento das capacidades de fala e compreensão auditiva, e sim leitura e escrita na LI. Já no item "9- Eu consigo fazer os exercícios das minhas folhas de atividades." as respostas nos trouxeram um feliz aceitamento de que os exercícios, apesar de desafiadores, estavam dentro da capacidade deles como alunos de sexto ano.

De modo geral, pudemos entender que os alunos apresentam maturidade suficiente para analisar o próprio processo de aprendizagem, já que suas respostas, muitas vezes, acabaram indo de encontro com a forma como nós, professora formada e professores em formação, pensávamos.

\subsection{Avaliação docente}

Além da autoavaliação, nós pedimos para que os alunos realizassem uma breve avaliação informal sobre os docentes, no caso sobre a professora supervisora e o grupo de bolsistas, em 
Dossiê Especial: Experiências do PIBID na formação inicial e continuada de professores de línguas estrangeiras

HIBARINO \& NODARI (orgs)

Revista X, vol.1, 2015

forma de comentários por escrito. Desde o primeiro momento eles já sabiam os motivos dessa atividade e a nossa intenção de continuar e aperfeiçoar o trabalho que já vínhamos fazendo. Os alunos não receberam perguntas a serem respondidas ou itens a guiarem suas respostas, pois queríamos que eles manifestassem suas opiniões de maneira anônima sobre as percepções gerais de nosso desempenho. Eles foram instruídos a não escrever seus nomes e a tentar escrever com letra diferenciada da usual. Reproduzimos alguns dos comentários para ilustrar alguns aspectos mencionados pelos alunos:

Aluno A: "4...Eu gosto da [pibidiana] porque ela repete pra gente falar inglês...gosto também do [pibidiano] porque quando a gente fala e acerta, ele fala: 'veigoudi'

Aluno B: "Espero que no próximo ano tenha mais canções e jogos"

Aluno C: “...A aula da professora \{se referindo à supervisora\} é muito boa, porque eu consigo entender bem."

Aluno D: "Professora \{se referindo à supervisora\} às vezes acho que falta algo em nossa aula, às vezes os alunos estão pra baixo e vocês \{se referindo ao grupo todo\} deixam agente mais pra baixo com algumas atividades que vocês passam, mas tem aulas que gosto tanto que não quero ir embora ..."

Como podemos perceber nos exemplos (B e D), os alunos mencionaram questões como o apreço que tinham pelos bolsistas e fizeram algumas sugestões em relação à aula de LI, tais como a realização de mais aulas na sala especial, frequentemente utilizada pelo outro sexto ano, além de mais músicas, filmes, jogos e trabalhos em dupla ou grupos.

Em relação ao comentário (A), percebe-se a importância da questão do elogio como um fator de motivação dos alunos na realização de suas atividades. Outro fator mencionado foi a estratégia de repetição utilizada por umas das pibidianas que auxilia, na perspectiva do aluno, na aprendizagem da LI. Diante desse comentário podemos perceber que os alunos conseguem ter uma visão mais crítica sobre o próprio processo de aprendizagem, já que conseguem distinguir aspectos que podem auxiliar ou não na aquisição da língua. Acreditamos que o fato de terem que realizar uma autoavaliação do que lhes foi apresentado ajudou nessa tomada de consciência.

O comentário do Aluno (D) revela algo que foi tratado com maior atenção pelo grupo e,

\footnotetext{
${ }^{4}$ Optamos por retirar os nomes de alunos, bolsistas e da professora supervisora a fim de preservar suas identidades.

${ }^{5}$ Optamos por manter os erros ortográficos que por ventura aparecessem.
} 
Dossiê Especial: Experiências do PIBID na formação inicial e continuada de professores de línguas estrangeiras

HIBARINO \& NODARI (orgs)

Revista X, vol.1, 2015

em especial, pelos bolsistas. Às vezes, mesmo preparando a aula com bastante atenção e empenho, algo durante a aplicação nos fazia sair de sala com uma sensação ruim, de que a aula não estava boa ou que havia faltado algo para ser melhor. Interessante verificar que os alunos também sabem quando algo não foi feito a contento, mostrando que eles têm consciência sobre como aprender e quando aprendem ou não, mesmo que os comentários ainda sejam no campo da percepção e não muito claros do que levaria a isso.

\section{Percepções sobre os comentários}

Nós mantivemos a mesma turma na transição de séries, então os planejamentos feitos para o andamento das atividades no ano seguinte levaram em consideração as avaliações realizadas no ano de 2013. Os resultados da avaliação docente foram analisados durante as férias e mudanças foram feitas no modo como as aulas foram preparadas, levando em consideração uma escolha mais cuidadosa dos exercícios a serem levados para a turma. Incluímos nas nossas práticas elogios falados e também o uso de carimbos com expressões de elogio em inglês, além de trazermos vídeos com mais frequência, levando-os para a tão desejada sala especial, mais propostas com músicas e jogos. Tais mudanças foram pensadas pelo grupo de bolsistas e acordadas com a professora supervisora e visaram atender às colocações feitas pelos alunos.

Mesmo no começo do ano de 2014 já foi possível verificar os efeitos de tais mudanças. Com aulas especialmente pensadas para eles, conseguimos fazer com que os alunos prestassem mais atenção e que mantivessem o comportamento e desempenho exemplares que fez deles uma turma modelo no ano anterior. Devido a alguns acontecimentos, acabamos perdendo alguns dias de aula e um efeito observado, muito apreciado pelos bolsistas, resultante disso, é que fomos recebidos em sala com ansiedade pelos alunos quando de nosso retorno.

As mudanças realizadas também impactaram a dinâmica das aulas. Ao propor atividades mais interativas, recebemos respostas mais coerentes e percebemos participação mais ativa por parte dos alunos nas atividades. Parece-nos também que, ao menos durante as aulas de inglês, os alunos se sentiram em um ambiente mais confortável para perguntar, além de que o medo de serem repreendidos por colegas diminuiu. Chamá-los ao quadro para que os próprios alunos 
Dossiê Especial: Experiências do PIBID na formação inicial e continuada de professores de línguas estrangeiras

HIBARINO \& NODARI (orgs)

Revista X, vol.1, 2015

corrigissem as atividades foi uma das práticas que funcionou nesse sentido.

\section{Considerações finais}

Trabalhar com alunos cuja grande maioria estava tendo contato formal com a LI pela primeira vez foi uma experiência muito gratificante e desafiadora. Apesar de reconhecermos que existia um pequeno conhecimento prévio sobre algumas situações e vocabulário, através de contato informal com a língua como anúncios, músicas e até estrangeirismos, apresentar o idioma aos alunos numa perspectiva formal, ou seja, o estudo da língua em sala de aula, foi um trabalho que exigiu grande responsabilidade por parte dos professores em formação inicial.

A realização tanto da autoavaliação discente quanto da avaliação docente nos fez repensar de que maneira o ambiente criado em sala de aula era saudável para o aprendizado e, devido a isso, passamos a prestar mais atenção nas metodologias e exercícios usados, a fim de proporcionar mais oportunidades e mais eficiência no aprendizado para que o desenvolvimento das múltiplas inteligências seja possível.

Após as análises, evidenciou-se como as percepções dos alunos podem ser distintas das que professores e bolsistas geralmente têm. No entanto, nem sempre essas percepções são levadas em consideração. A desmotivação e a falta de interesse por parte de alguns alunos pode ser resultado da falta de oportunidade desse aluno de sugerir formas alternativas de aprendizagem. A voz dos alunos precisa ser ouvida já que eles fazem parte ativa desse processo. Além disso, os estudantes podem dar contribuições valiosas que podem ser incorporadas em outras classes e favorecer a aprendizagem de outros estudantes.

Em se tratando do papel da avaliação, acreditamos que é crucial incluir o instrumento de autoavaliação de forma mais recorrente para que não só o aluno reflita sobre a sua aprendizagem, mas também o professor possa direcionar a sua prática pedagógica de maneira mais informada, pois está levando em consideração os interesses e as necessidades de seus alunos.

\section{Referências}

BROWN, D. H.. Language assessment: principles and classroom practices. Longman: USA, New York. 2004. 
Dossiê Especial: Experiências do PIBID na formação inicial e continuada de professores de línguas estrangeiras

HIBARINO \& NODARI (orgs)

Revista X, vol.1, 2015

CABRAL, E. A., MULIK, K. B., "A avaliação de línguas estrangeiras na perspectiva das inteligências múltiplas". IN: MULIK, K. B., RETORTA, M. S.. Avaliação no EnsinoAprendizagem de Línguas Estrangeiras: Diálogos, Pesquisas e Reflexões. Campinas: Pontes Editores, 2014.

GENESEE, F. \& UPSHUR, J.. A Classroom-Based Evaluation in Second Language Education. Cambridge: CUP, 2009.

HOFFMANN, J.M.L.. Avaliação mediadora: uma prática em construção da pré-escola à universidade. 28 ed. Porto Alegre: Mediação, 2009.

JORDÃO, C. M. et. Al.. "Letramento Crítico em 2.500 palavras, mais ou menos...”. IN: ALBUQUERQUE, M. V. de; BREDA, F.; EDMUNDO, E. S. G.; GOMES, H. O.; JORDÃO, C. M.; OLIVEIRA, L. C. de, ROSA, A. da; \& TRINKEL, M. C.. O PIBID-UFPR nas Aulas de Inglês: divisor de águas e formador de marés. Campinas: Pontes, 2013.

MITRE, S. [et.al].. Metodologias ativas de ensino-aprendizagem na formação profissional em saúde: debates atuais. Ciência \& Saúde Coletiva, 13(Sup 2), Pp. 2133-2144, 2008. Disponível em: http://www.scielosp.org/pdf/csc/v13s2/v13s2a18.pdf. Acesso em 26 mar. 2014.

MOROSOV, I.; MARTINEZ, J. Z.. A didática do ensino e a avaliação da aprendizagem em língua estrangeira. Curitiba: IBPEX, 2008.

SILVA, K. A. da., BARTHOLOMEU, M. A. N., \& CLAUS, M. M. K.. "Auto-avaliação: uma alternativa contemporânea do processo avaliativo". IN: Revista Brasileira de Linguística Aplicada. vol. 7, núm. 1, Belo Horizonte: UFMG, 2007, Pp. 89-115.

WEININGER, M. J.. "Do Aquário em Direção ao Mar Aberto Mudanças no Papel do Professor e do Aluno". IN: LEFFA, V. (org). O Professor de Línguas Estrangeiras: Construindo a Profissão. Pelotas: Educat, 2006. 